\title{
Erratum to: Increasing Cancer Screening for Latinas: Examining the Impact of Health Messages and Navigation in a Cluster-Randomized Study
}

Lina Jandorf • Mindy Feldman Hecht • Gary Winkel • Linda D. Thélémaque • Frances G. Saad-Harfouche • Zoran Bursac • Paul Greene • Deborah O. Erwin

Published online: 24 May 2014

(C) W. Montague Cobb-NMA Health Institute 2014

Erratum to: J. Racial and Ethnic Health Disparities

DOI 10.1007/s40615-014-0014-6

Lina Jandorf is listed as the first and last author. She should be the first author and Deborah O. Erwin should be the last author.

The online version of the original article can be found at http://dx.doi.org/ 10.1007/s40615-014-0014-6.

L. Jandorf $(\bowtie) \cdot$ M. F. Hecht $\cdot$ G. Winkel $\cdot$ L. D. Thélémaque Department of Oncological Sciences, Mount Sinai School of Medicine, One Gustave L. Levy Place, Box 1130, New York, NY 10029, USA

e-mail: Lina.jandorf@mssm.edu

F. G. Saad-Harfouche

Division of Cancer Control Prevention \& Population Science, Roswell Park Cancer Institute, Elm \& Carlton Streets, Buffalo, NY 14263, USA

Z. Bursac

Department of Biostatistics, Fay W. Boozman College of Public Health, College of Medicine, University of Arkansas for Medical Sciences, 4301W. Markham, Slot 781, Little Rock, AR 72205, USA

P. Greene

Department of Health Behavior and Health Education, University of Arkansas for Medical Sciences College of Public Health, Little Rock, AR 72205, USA

D. O. Erwin

Division of Cancer Prevention and Population Sciences, Roswell Park Cancer Institute, Elm \& Carlton Streets, Buffalo, NY 14263, USA 